\title{
Common Fixed Point Theorem of Two Mappings Satisfying a Generalized Weak Contractive Condition
}

\author{
M. Abbas and M. Ali Khan \\ Department of Mathematics, Lahore University of Management Sciences, Lahore 54792, Pakistan \\ Correspondence should be addressed to M. Abbas, mujahid@lums.edu.pk
}

Received 6 August 2009; Accepted 11 November 2009

Recommended by Evgeny Korotyaev

Existence of common fixed point for two mappings which satisfy a generalized weak contractive condition is established. As a consequence, a common fixed point result for mappings satisfying a contractive condition of integral type is obtained. Our results generalize, extend, and unify several well-known comparable results in literature.

Copyright $@ 2009$ M. Abbas and M. A. Khan. This is an open access article distributed under the Creative Commons Attribution License, which permits unrestricted use, distribution, and reproduction in any medium, provided the original work is properly cited.

\section{Introduction and Preliminaries}

Let $X$ be a metric space and $T: C \rightarrow C$ a mapping. Recall that $T$ is contraction if $d(T x, T y) \leq$ $k d(x, y)$ for all $x, y \in X$, where $0 \leq k<1$. A point $x \in C$ is a fixed point of $T$ provided $T x=x$. If a map $T$ satisfies $F(T)=F\left(T^{n}\right)$ for each $n \in N$, where $F(T)$ denotes the set of all fixed points of $T$, then it is said to have property $P$. Banach contraction principle which gives an answer on existence and uniqueness of a solution of an operator equation $T x=$ $x$ is the most widely used fixed point theorem in all of analysis. Branciari [1] obtained a fixed point theorem for a mapping satisfying an analogue of Banach's contraction principle for an integral type inequality. Akgun and Rhoades [2] have shown that a map satisfying a Meir- Keeler type contractive condition of integral type has a property $P$. Rhoades and Abbas [3] extended [4, Theorem 1] for mappings satisfying contractive condition of integral type. They also studied several results for maps which have property $P$, defined on a metric space satisfying generalized contractive conditions of integral type. Rhoades [5] proved two fixed point theorems involving more general contractive condition of integral type (see, also [6,7]). If maps $S$ and $T$ satisfy $F(S) \cap F(T)=F\left(S^{n}\right) \cap F\left(T^{n}\right)$ for each $n \in N$, then they are said to have property $Q$. Jeong and Rhoades [8] studied the property $Q$ for pairs of maps satisfying a number of contractive conditions. 
Recently Dutta and Choudhury [9] gave a generalization of Banach contraction principle, which in turn generalize [4, Theorem 1] and corresponding result of [10]. Sessa [11] defined the concept of weakly commuting to obtain common fixed point for pairs of maps. Jungck generalized this idea, first to compatible mappings [12] and then to weakly compatible mappings [13]. There are examples that show that each of these generalizations of commutativity is a proper extension of the previous definition. The aim of this paper is to present a common fixed point theorem for weakly compatible maps satisfying a generalized weak contractive condition which is more general than the corresponding contractive condition of integral type. Our results substantially extend, improve, and generalize comparable results in literature [3,14,15].

The following definitions and results will be needed in the sequel.

Definition 1.1. Let $X$ be a set, and $f, g$ selfmaps of $X$. A point $x$ in $X$ is called a coincidence point of $f$ and $g$ if and only if $f x=g x$. We will call $w=f x=g x$ a point of coincidence of $f$ and $g$.

Definition 1.2. Two maps $f$ and $g$ are said to be weakly compatible if they commute at their coincidence points.

Lemma 1.3 (see [16]). Let $f$ and $g$ be weakly compatible self maps of a set X. If $f$ and $g$ have a unique point of coincidence $w$ (say), then $w$ is the unique common fixed point of $f$ and $g$.

\section{A Common Fixed Point Theorem}

Set $\digamma=\left\{\phi: R^{+} \rightarrow R^{+}: \phi\right.$ is a Lebesgue integrable mapping which is summable and nonnegative and satisfies $\int_{0}^{\varepsilon} \phi(t) d t>0$, for each $\left.\varepsilon>0\right\}$ and $G=\{\psi:[0, \infty] \rightarrow[0, \infty]: \psi$ is continuous and nondecreasing mapping with $\psi(t)=0$ if and only if $t=0\}$.

The following is the main result of this paper.

Theorem 2.1. Let $f, g$ be two self maps of a metric space $(X, d)$ satisfying

$$
\psi(d(f x, f y)) \leq \psi(d(g x, g y))-\varphi(d(g x, g y))
$$

for all $x, y \in X$, where $\psi, \varphi \in G$. If range of $g$ contains the range of $f$ and $g(X)$ is a complete subspace of $X$, then $f$ and $g$ have a unique point of coincidence in $X$. Moreover if $f$ and $g$ are weakly compatible, $f$ and $g$ have a unique common fixed point.

Proof. Let $x_{0}$ be an arbitrary point of $X$. Choose a point $x_{1}$ in $X$ such that $f\left(x_{0}\right)=g\left(x_{1}\right)$. This can be done, since the range of $g$ contains the range of $f$. Continuing this process, having chosen $x_{n}$ in $X$, we obtain $x_{n+1}$ in $X$ such that $f\left(x_{n}\right)=g\left(x_{n+1}\right), n=0,1,2, \ldots$ Suppose for any $n, g\left(x_{n}\right) \neq g\left(x_{n+1}\right)$, since, otherwise, $f$ and $g$ have a point of coincidence. From (2.1), we have

$$
\begin{aligned}
\psi\left(d\left(g x_{n+1}, g x_{n}\right)\right) & =\psi\left(d\left(f x_{n}, f x_{n-1}\right)\right) \\
& \leq \psi\left(d\left(g x_{n}, g x_{n-1}\right)\right)-\varphi\left(d\left(g x_{n}, g x_{n-1}\right)\right) \\
& <\psi\left(d\left(g x_{n}, g x_{n-1}\right)\right)
\end{aligned}
$$


that is, $\psi\left(d\left(g x_{n+1}, g x_{n}\right)\right)<\psi\left(d\left(g x_{n}, g x_{n-1}\right)\right)$, and hence

$$
d\left(g x_{n}, g x_{n+1}\right) \leq d\left(g x_{n}, g x_{n-1}\right)
$$

It follows that $\left\{d\left(g x_{n}, g x_{n+1}\right)\right\}$ is monotone decreasing sequence of numbers and consequently there exists $r \geq 0$ such that $d\left(g x_{n}, g x_{n+1}\right) \rightarrow r$ as $n \rightarrow \infty$. Suppose that $r>0$, then

$$
\begin{aligned}
0 & <\psi(r) \leq \psi\left(d\left(g x_{n+1}, g x_{n}\right)\right)=\psi\left(d\left(f x_{n}, f x_{n-1}\right)\right) \\
& \leq \psi\left(d\left(g x_{n}, g x_{n-1}\right)\right)-\varphi\left(d\left(g x_{n}, g x_{n-1}\right)\right)
\end{aligned}
$$

which on taking limit as $n \rightarrow \infty$ yields

$$
\psi(r) \leq \psi(r)-\varphi(r)<\psi(r)
$$

which is a contradiction. Therefore $r=0$. Now we prove that $\left\{g x_{n}\right\}$ is a Cauchy sequence. If not, then there exist some $\varepsilon>0$ and subsequences $\left\{g x_{n_{k}}\right\}$ and $\left\{g x_{m_{k}}\right\}$ of $\left\{g x_{n}\right\}$ with $k<$ $n_{k}<m_{k}$ such that $d\left(g x_{n_{k}}, g x_{m_{k}}\right) \geq 3 \varepsilon$ for each $k$. As $d\left(g x_{n_{k}+1}, g x_{n_{k}}\right) \rightarrow 0$ as $k \rightarrow \infty$, for large enough $k$, we have $d\left(g x_{n_{k}+1}, g x_{n_{k}}\right)<\varepsilon$ and $d\left(g x_{m_{k}+1}, g x_{m_{k}}\right)<\varepsilon$. Thus we obtain

$$
\begin{aligned}
d\left(g x_{n_{k}+1}, g x_{m_{k}}\right) & \geq d\left(g x_{n_{k}}, g x_{m_{k}}\right)-d\left(g x_{n_{k}+1}, g x_{n_{k}}\right)>\varepsilon \\
d\left(g x_{n_{k}+1}, g x_{m_{k}-1}\right) & \geq d\left(g x_{n_{k}}, g x_{m_{k}}\right)-d\left(g x_{m_{k}-1}, g x_{m_{k}}\right)-d\left(g x_{n_{k}+1}, g x_{n_{k}}\right) \\
& >\varepsilon .
\end{aligned}
$$

We may assume that $n_{k}$ are even and $m_{k}$ are odd and that $d\left(g x_{n_{k}}, g x_{m_{k}}\right)>\varepsilon$ for all $k$. Put

$$
r_{k}=\min \left\{m_{k}: d\left(g x_{n_{k}}, g x_{m_{k}}\right)>\varepsilon\right\}
$$

Now,

$$
\varepsilon<d\left(g x_{n_{k}}, g x_{r_{k}}\right) \leq d\left(g x_{n_{k}}, g x_{r_{k}-2}\right)+d\left(g x_{r_{k}-2}, g x_{r_{k}-1}\right)+d\left(g x_{r_{k}-1}, g x_{r_{k}}\right)
$$

implies that $d\left(g x_{n_{k}}, g x_{r_{k}}\right) \rightarrow \varepsilon$ as $k \rightarrow \infty$. Furthermore

$$
\begin{aligned}
& d\left(g x_{n_{k}}, g x_{r_{k}}\right)-d\left(g x_{n_{k}}, g x_{n_{k}+1}\right)-d\left(g x_{r_{k}}, g x_{r_{k}+1}\right) \\
& \quad \leq d\left(g x_{n_{k}+1}, g x_{r_{k}+1}\right) \leq d\left(g x_{n_{k}}, g x_{r_{k}}\right)+d\left(g x_{n_{k}}, g x_{n_{k}+1}\right)+d\left(g x_{r_{k}}, g x_{r_{k}+1}\right)
\end{aligned}
$$


gives $d\left(g x_{n_{k}+1}, g x_{r_{k}+1}\right) \rightarrow \varepsilon$, as $k \rightarrow \infty$. Therefore

$$
\begin{aligned}
\psi\left(d\left(g x_{n_{k}+1}, g x_{r_{k}+1}\right)\right) & =\psi\left(d\left(f x_{n_{k}}, f x_{r_{k}}\right)\right) \\
& \leq \psi\left(d\left(g x_{n_{k}}, g x_{r_{k}}\right)\right)-\varphi\left(d\left(g x_{n_{k}}, g x_{r_{k}}\right)\right) .
\end{aligned}
$$

Taking limit as $k \rightarrow \infty$ yields

$$
\psi(\varepsilon) \leq \psi(\varepsilon)-\varphi(\varepsilon)
$$

which is a contradiction. Hence $\left\{g x_{n}\right\}$ is a Cauchy sequence. From completeness of $g(X)$, there exists a point $q$ in $g(X)$ such that $g x_{n} \rightarrow q$ as $n \rightarrow \infty$. Consequently, we can find $p$ in $X$ such that $g(p)=q$. Now

$$
\begin{aligned}
\psi\left(d\left(g x_{n+1}, f p\right)\right) & =\psi\left(d\left(f x_{n}, f p\right)\right) \\
& \leq \psi\left(d\left(g x_{n}, g p\right)\right)-\varphi\left(d\left(g x_{n}, g p\right)\right)
\end{aligned}
$$

on taking limit as $n \rightarrow \infty$ implies

$$
\psi(d(q, f p)) \leq \psi(0)-\varphi(0)
$$

$\psi(d(q, f p))=0$, and $f(p)=q$. Hence $q$ is the point of coincidence of $f$ and $g$. Assume that there is another point of coincident $r$ in $X$ such that $r \neq q$. Then there exists $s$ in $X$ such that $f(s)=g(s)=r$. Using (2.1), we have

$$
\begin{aligned}
\psi(d(g p, g s)) & =\psi(d(f p, f s)) \\
& \leq \psi(d(g p, g s))-\varphi(d(g p, g s)) \\
& <\psi(d(g p, g s)),
\end{aligned}
$$

which is a contradiction which proves the uniqueness of point of coincidence; the result now follows from Lemma 1.3

Corollary 2.2. Let $f, g$ be two self maps of a metric space $(X, d)$ satisfying

$$
\int_{0}^{\psi(d(f x, f y))} \phi(t) d t \leq \int_{0}^{\psi(d(g x, g y))} \phi(t) d t-\int_{0}^{\varphi(d(g x, g y))} \phi(t) d t
$$

for all $x, y \in X$, where $\phi \in \digamma$ and $\psi, \varphi \in G$. If range of $g$ contains the range of $f$ and $g(X)$ is a complete subspace of $X$, then $f$ and $g$ have a unique point of coincidence in X. Moreover if $f$ and $g$ are weakly compatible, $f$ and $g$ have a unique common fixed point. 
Proof. Define $\Phi: R^{+} \rightarrow R^{+}$by $\Phi(x)=\int_{0}^{x} \phi(t) d t$, then $\Phi \in G$ and (2.15) becomes

$$
\Phi(\psi(d(f x, f y))) \leq \Phi(\psi(d(g x, g y)))-\Phi(\varphi(d(g x, g y)))
$$

which further can be written as

$$
\psi_{1}(d(f x, f y)) \leq \psi_{1}(d(g x, g y))-\varphi_{1}(d(g x, g y))
$$

where $\psi_{1}=\Phi \circ \psi$ and $\varphi_{1}=\Phi \circ \varphi \in G$. Clearly $\psi_{1}, \varphi_{1} \in G$. Hence by Theorem $2.1 f$ and $g$ have unique common fixed point.

Now we present two examples in the support of Theorem 2.1.

Example 2.3. Let $X=[0,1] \cup\{2,3,4, \ldots\}$,

$$
d(x, y)= \begin{cases}|x-y|, & \text { if } x, y \in[0,1], x \neq y, \\ x+y, & \text { if at least one of } x \text { or } y \notin[0,1], x \neq y \\ 0, & \text { if } x=y\end{cases}
$$

Then $(X, d)$ is a complete metric space [17]. Consider $f: X \rightarrow X$, and $\psi, \varphi \in G$ as given in [9]:

$$
\begin{gathered}
f x= \begin{cases}x-\frac{1}{2} x^{2}, & \text { if } 0 \leq x \leq 1, \\
x-1, & \text { if } x>1\end{cases} \\
\psi(t)= \begin{cases}t, & \text { if } 0 \leq t \leq 1 \\
t^{2}, & \text { if } t \geq 1\end{cases} \\
\varphi(t)= \begin{cases}\frac{1}{2} t^{2}, & \text { if } 0 \leq t \leq 1 \\
\frac{1}{2}, & \text { if } t \geq 1\end{cases}
\end{gathered}
$$

Let $g: X \rightarrow X$ be defined as

$$
g x= \begin{cases}x, & \text { if } 0 \leq x \leq 1 \\ x+1, & \text { if } x>1\end{cases}
$$


Assume that $x>y$ and discuss the following cases.

When $x \in[0,1]$, then

$$
\begin{aligned}
\psi(d(f x, f y)) & =\left(x-\frac{1}{2} x^{2}\right)-\left(y-\frac{1}{2} y^{2}\right) \\
& \leq(x-y)-\frac{1}{2}(x-y)^{2} \\
& =\psi(d(g x, g y))-\varphi(d(g x, g y))
\end{aligned}
$$

Taking $x$ in $\{3,4, \ldots\}$, and $y$ in $[0,1]$, we obtain

$$
\begin{aligned}
\psi(d(f x, f y)) & =\left(x-1+y-\frac{1}{2} y^{2}\right)^{2} \\
& \leq(x+y-1)^{2} \\
\psi(d(g x, g y)) & =(x+y+1)^{2} \\
\varphi(d(g x, g y)) & =\frac{1}{2} .
\end{aligned}
$$

Hence

$$
\psi(d(f x, f y)) \leq \psi(d(g x, g y))-\varphi(d(g x, g y))
$$

Now, when $x \in\{3,4, \ldots\}$, and $y \notin[0,1]$, then

$$
\begin{aligned}
\psi(d(f x, f y)) & =(x-1+y-1)^{2} \\
< & (x+y-1)^{2} \\
\psi(d(g x, g y)) & =(x+y+2)^{2}, \\
\varphi(d(g x, g y)) & =\frac{1}{2} .
\end{aligned}
$$

Obviously (2.31) holds. Finally when $x=2$, we have $y \in[0,1], f x=1$, and

$$
d(f x, f y)=1-\left(y-\frac{1}{2} y^{2}\right) \leq 1
$$


so that $\psi(d(f x, f y)) \leq 1$, then

$$
\begin{aligned}
\psi(d(g x, g y))-\varphi(d(g x, g y)) & =(3+y)^{2}-\frac{1}{2} \\
& >1 \geq \psi(d(f x, f y))
\end{aligned}
$$

Thus all conditions of Theorem 2.1 are satisfied. Moreover $f$ and $g$ have a unique common fixed point.

Example 2.4. Let $X=[0,1]$ and $f, g: X \rightarrow X$ be given as

$$
f(x)=\frac{2}{5} x^{2}+\frac{3}{5}, \quad g(x)=\frac{2}{3} x^{2}+\frac{1}{3} .
$$

Consider $\psi, \varphi \in G$ as $\psi(t)=(1 / 2) t$ and $\varphi(t)=(1 / 10) t$. Then we have

$$
\begin{aligned}
\psi(d(f x, f y)) & =\frac{2}{10}\left|x^{2}-y^{2}\right| \\
& \leq \frac{1}{2} \frac{2}{3}\left|x^{2}-y^{2}\right|-\frac{1}{10} \frac{2}{3}\left|x^{2}-y^{2}\right| \\
& =\psi(d(g x, g y))-\varphi(d(g x, g y)) .
\end{aligned}
$$

Note that $x=1$ is the unique coincidence point of $f$ and $g$, and $f$ and $g$ are commuting at $x=1$. Hence all conditions of Theorem 2.1 are satisfied. Moreover, $x=1$ is the unique common fixed point of $f$ and $g$.

Following theorem can be viewed as generalization and extension of [3, Theorem 3].

Theorem 2.5. Let $f$ be a self map of a complete metric space $(X, d)$ satisfying

$$
\int_{0}^{\psi(d(f x, f y))} \phi(t) d t \leq \int_{0}^{\psi(d(x, y))} \phi(t) d t-\int_{0}^{\varphi(d(x, y))} \phi(t) d t
$$

for all $x, y \in X$, where $\phi \in \digamma$ and $\psi, \varphi \in G$. Then $f$ has a unique fixed point. Moreover $f$ has property $P$. 
Proof. Existence and uniqueness of fixed point of $f$ follows from Corollary 2.2. Now we prove that $f$ has property $P$. Let $u \in F\left(f^{n}\right)$. We shall always assume that $n>1$, since the statement for $n=1$ is trivial. We claim that $f u=u$. If not, then, by (2.31),

$$
\begin{aligned}
\int_{0}^{\psi(d(u, f u))} \phi(t) d t & =\int_{0}^{\psi\left(d\left(f^{n} u, f\left(f^{n} u\right)\right)\right)} \phi(t) d t=\int_{0}^{\psi\left(d\left(f\left(f^{n-1} u\right), f\left(f^{n} u\right)\right)\right)} \phi(t) d t \\
& \leq \int_{0}^{\psi\left(d\left(f^{n-1} u, f^{n} u\right)\right)} \phi(t) d t-\int_{0}^{\varphi\left(d\left(f^{n-1} u, f^{n} u\right)\right)} \phi(t) d t \\
& \leq \int_{0}^{\psi\left(d\left(f^{n-1} u, f^{n} u\right)\right)} \phi(t) d t=\int_{0}^{\psi\left(d\left(f\left(f^{n-2} u\right), f\left(f^{n-1} u\right)\right)\right)} \phi(t) d t \\
& \leq \int_{0}^{\psi\left(d\left(f^{n-2} u, f^{n-1} u\right)\right)} \phi(t) d t-\int_{0}^{\varphi\left(d\left(f^{n-2} u, f^{n-1} u\right)\right)} \phi(t) d t \\
& \leq \int_{0}^{\psi\left(d\left(f^{n-2} u, f^{n-1} u\right)\right)} \phi(t) d t .
\end{aligned}
$$

Continuing this process we arrive at

$$
\begin{aligned}
\int_{0}^{\psi(d(u, f u))} \phi(t) d t & \leq \int_{0}^{\psi(d(u, f u))} \phi(t) d t-\int_{0}^{\varphi(d(u, f u))} \phi(t) d t \\
& <\int_{0}^{\psi(d(u, f u))} \phi(t) d t
\end{aligned}
$$

which is a contradiction. Hence the result follows.

Remarks 2.6. Existence and uniqueness of fixed point of $f$ in above theorem also follows from [9, Theorem 1].

Remarks 2.7. (a) It is noted that if maps $f$ and $g$ involved in Theorem 2.1 are commuting, then they have property $Q$.

(b) Suzuki [18] observed that Branciari [1, Theorem 1] is a particular case of MeirKeeler fixed point theorem [19]. We pose an open problem to see if a link exists between the contractive conditions (2.15) and the Meir-Keeler condition.

\section{Acknowledgment}

The authors are thankful to referees for their precise remarks to improve the presentation of the paper. 


\section{References}

[1] A. Branciari, "A fixed point theorem for mappings satisfying a general contractive condition of integral type," International Journal of Mathematics and Mathematical Sciences, vol. 29, no. 9, pp. 531536, 2002.

[2] F. A. Akgun and B. E. Rhoades, "Maps satisfying a Meir-Keeler type contractive conditions of integral type for which $F(T)=F\left(T^{n}\right)$," In press.

[3] B. E. Rhoades and M. Abbas, "Maps satisfying generalized contractive conditions of integral type for which $F(T)=F\left(T^{n}\right)$," International Journal of Pure and Applied Mathematics, vol. 45, no. 2, pp. 225-231, 2008.

[4] B. E. Rhoades, "Some theorems on weakly contractive maps," Nonlinear Analysis: Theory, Methods $\mathcal{E}$ Applications, vol. 47, no. 4, pp. 2683-2693, 2001.

[5] B. E. Rhoades, "Two fixed-point theorems for mappings satisfying a general contractive condition of integral type," International Journal of Mathematics and Mathematical Sciences, vol. 2003, no. 63, pp. 4007-4013, 2003.

[6] A. Aliouche, "A common fixed point theorem for weakly compatible mappings in symmetric spaces satisfying a contractive condition of integral type," Journal of Mathematical Analysis and Applications, vol. 322, no. 2, pp. 796-802, 2006.

[7] P. Vijayaraju, B. E. Rhoades, and R. Mohanraj, “A fixed point theorem for a pair of maps satisfying a general contractive condition of integral type," International Journal of Mathematics and Mathematical Sciences, vol. 2005, no. 15, pp. 2359-2364, 2005.

[8] G. S. Jeong and B. E. Rhoades, "Maps for which $F(T)=F\left(T^{n}\right)$," Fixed Point Theory, vol. 6, pp. 87-131, 2005.

[9] P. N. Dutta and B. S. Choudhury, "A generalisation of contraction principle in metric spaces," Fixed Point Theory and Applications, vol. 2008, Article ID 406368, 8 pages, 2008.

[10] Ya. I. Alber and S. Guerre-Delabriere, "Principle of weakly contractive maps in Hilbert spaces," in New Results in Operator Theory and Its Applications, I. Gohberg and Y. Lyubich, Eds., vol. 98 of Operator Theory: Advances and Applications, pp. 7-22, Birkhäuser, Basel, Switzerland, 1997.

[11] S. Sessa, "On a weak commutativity condition of mappings in fixed point considerations," Publications de l'Institut Mathématique, vol. 32, pp. 149-153, 1982.

[12] G. Jungck, "Compatible mappings and common fixed points," International Journal of Mathematics and Mathematical Sciences, vol. 9, no. 4, pp. 771-779, 1986.

[13] G. Jungck, "Common fixed points for noncontinuous nonself maps on nonmetric spaces," Far East Journal of Mathematical Sciences, vol. 4, no. 2, pp. 199-215, 1996.

[14] I. Beg and M. Abbas, "Coincidence point and invariant approximation for mappings satisfying generalized weak contractive condition," Fixed Point Theory and Applications, vol. 2006, Article ID 74503, 7 pages, 2006.

[15] M. S. Khan, M. Swaleh, and S. Sessa, "Fixed point theorems by altering distances between the points," Bulletin of the Australian Mathematical Society, vol. 30, no. 1, pp. 1-9, 1984.

[16] M. Abbas and G. Jungck, "Common fixed point results for noncommuting mappings without continuity in cone metric spaces," Journal of Mathematical Analysis and Applications, vol. 341, no. 1, pp. 416-420, 2008.

[17] D. W. Boyd and J. S. Wong, "On nonlinear contractions," Proceedings of the American Mathematical Society, vol. 20, pp. 458-464, 1969.

[18] T. Suzuki, "Meir-Keeler contractions of integral type are still Meir-Keeler contractions," International Journal of Mathematics and Mathematical Sciences, vol. 2007, Article ID 39281, 6 pages, 2007.

[19] A. Meir and E. Keeler, "A theorem on contraction mappings," Journal of Mathematical Analysis and Applications, vol. 28, no. 2, pp. 326-329, 1969. 


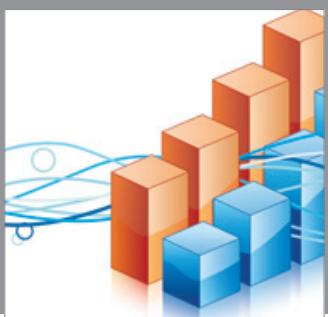

Advances in

Operations Research

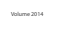

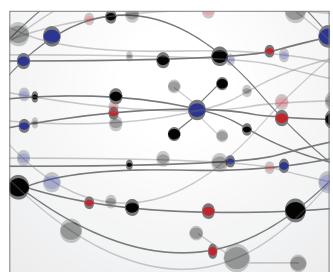

\section{The Scientific} World Journal
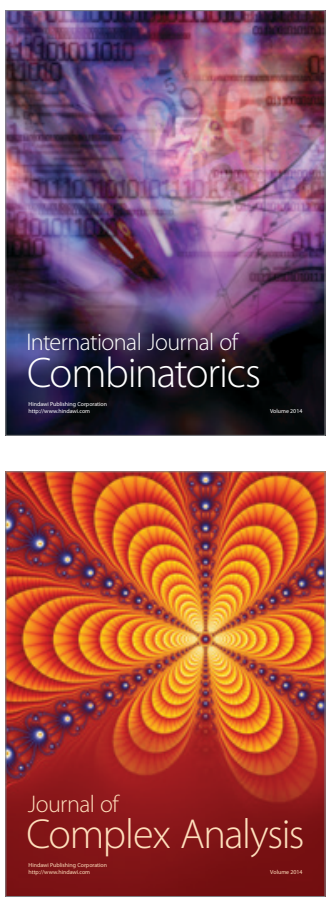

International Journal of

Mathematics and

Mathematical

Sciences
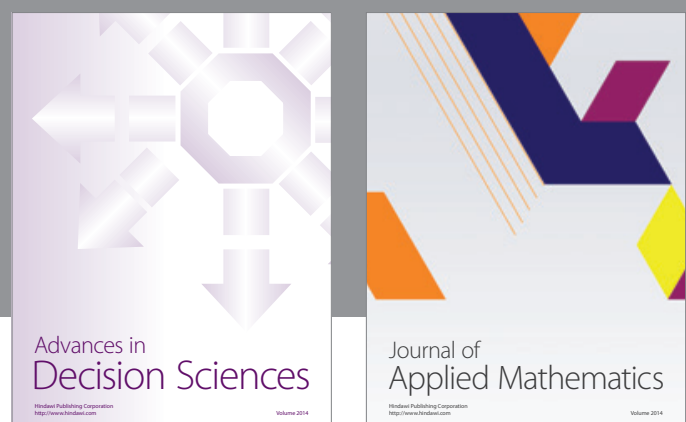

Journal of

Applied Mathematics
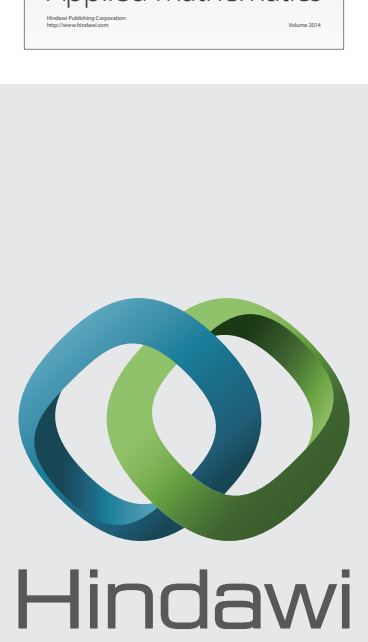

Submit your manuscripts at http://www.hindawi.com
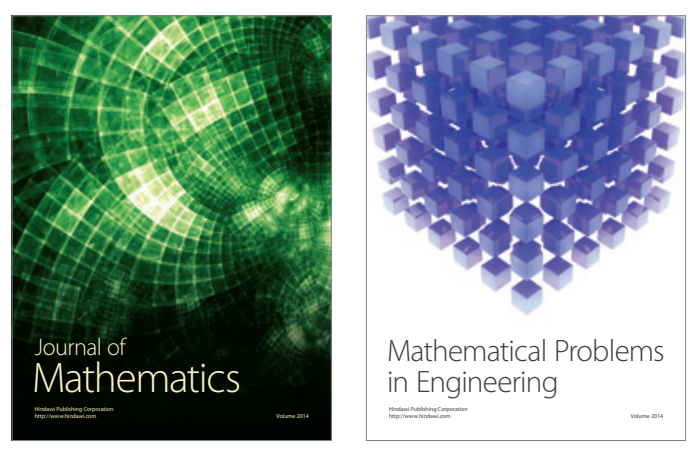

Mathematical Problems in Engineering
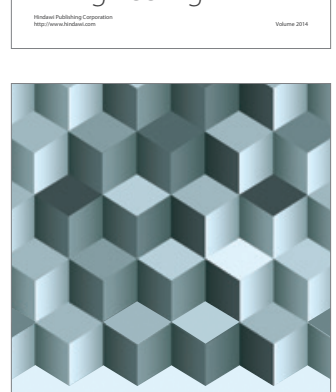

Journal of

Function Spaces
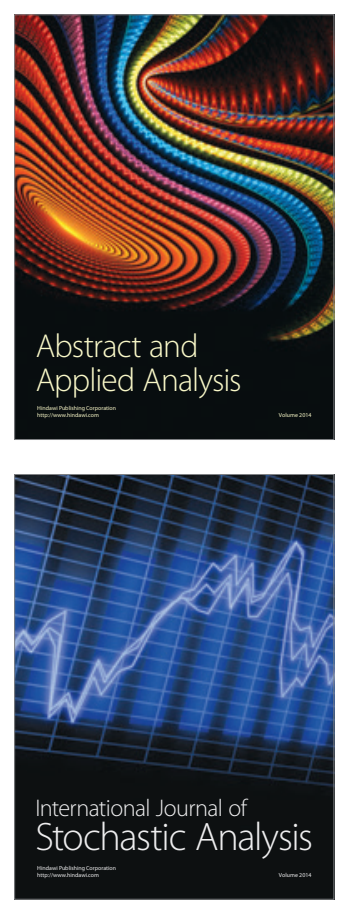

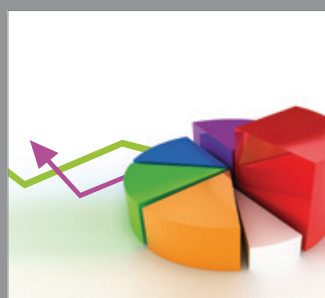

ournal of

Probability and Statistics

Promensencen
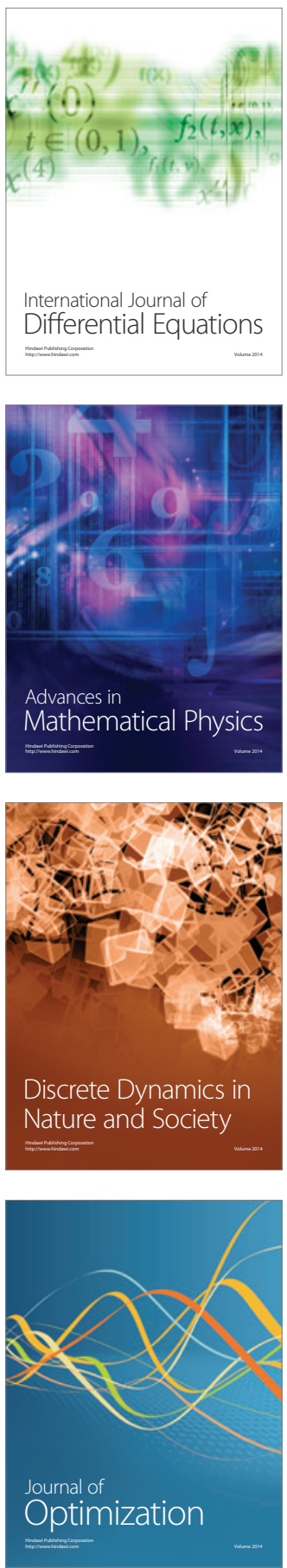